affect the occurrence of the seizures was discussed. E. A. Swinyard (University of Utah) compared the seizures induced by electro-shock, metrazol and audiogenic stimuli in audiogenic-seizure-susceptible mice of different selected strains. He found that the patterns of maximal seizures induced by these different methods were very similar, but that the seizure susceptibility of the mice varied in responso to tho differont stimuli. The sensitivity of all his strains to motrazol was similar, but he was able to demonstrate significant differences to drugs which depress tho central nervous system when mice in the different strains were subjected to cloctro-shock and audiogenic seizures. These pharmacological observations were supported by the report of M. Niaussat and P. Laget (Centro National de la Rechorche Scientifique, France), who demonstrated differences in the electro-encephalograms of mice with audiogenic and metrazol-induced scizures, A. Lohmann and R.-G. Busnel (Centro National de la Recherche Scientifique, France) reported their investigations on the uso of drugs which altered sorotonin-levels in the brain in scizure-susceptible mico. They found that the concentration of serotonin was identical in both susceptible and resistant sub-lines and that audiogenic seizuros did not change it. Howevor, they found that a decrease in the concentration of serotonin produced by reserpine increasod the intensity of the convulsions, and that an increase in the level produced by monoamine inhibitors, serotonin itself, or its predecessors decreased the intensity of the convulsions.

N. Plotnikoff (Stanford Research Institute, California) showed how drugs could be used to investigate different phases of the audiogenic seizure. He found that tranquillizers could provent the pre-convulsivo phase of wild-running and convulsions, whereas sedatives prevented only the convulsive phase in his strains. If tho mice were given an opportunity to escape from the chambor during the audiogenic stimulus, he found that the escape response could be differentially inhibited by sedativo and tranquillizing drugs. The different strains which he used varied in their responso to difforent pharmacological agonts, and he suggested that differential inbroeding of suscoptible mice could provide a convenient tool for nourochemical investigations of the mochanisms of drugs.

There was ample time for discussion of the points which were raised in all the papers; contributions from those who were working on the different disciplines enabled the participants to discover the advantages of working with physiological phonomena of this nature, and also to appreciato the shortcomings of the methods which they were using. It became clear that several differont species react to an audiogenic stimulus by abnormal bohaviour. This behaviour generally takes the form of a soizure which is characterized by a phase of running, clonic and tonic phasos. The details and order of these phases vary from spocies to species and with different strains in the species. Alterations in the form of the seizures can also be induced by changing the sound stimulus, the animals' environment, diet and various other factors. Drugs may intensify, inhibit or otherwise change the severity and sequence of events in the seizures. It became clear that the audiogenic seizure could provide a ficld of interest for further investigations in many difforent disciplines; tho pooling of the knowledge from these different disciplines stimulated discussion and thought about the physiology of the brain, and the ways in which the audiogenic seizure could be used as a model for discovering moro about human opilepsy.

It was realized during the courso of the colloquium that it would bo necessary to standardize the descriptions and nomenclature of the different phases of the audiogenic seizure. It was agreed that all known strains in all species which are susceptible to audiogenic seizures should be registered, and that workers in this field should attompt to maintain pure lines among their strains and roport any alterations in their characters. In order to co-ordinate work with audiogenic seizure susceptible strains of animals, and to assist any workers who wish to obtain susceptible animals for their investigations, an international committee was appointed with two represontatives from each of the participating countries. The British representatives are M. R. $\Lambda$. Chance (University of Birmingham) and C. W. M. Wilson (University of Liverpool). It was arranged that the proceedings of the colloquium would be published by the Centre National de la Rechercho Scientifique; this publication will contain a complete bibliography of all the papers which have been published on audiogenic seizures. It is proposed that the publication will also contain the recommendations of the committee regarding the nomenclature and description of the $\begin{array}{ll}\text { audiogenic seizure. } & \text { C. W. M. WILson }\end{array}$

\title{
PRESENTATION OF SCIENCE THROUGH TELEVISION
}

IN a Cantor Lecture delivered to the Royal Socioty 1 of Arts on May 1, 1961, Dr. Tom A. Margerison described how science could bo presented on television not only to the specialist audience but especially to the layman ${ }^{1}$. In spite of the absolute nocessity of science and technology, the 10-15 per cont of the population who guido the destiny of Britain, the professional men, the majority of teachers, the industrialists. the politicians, are almost completely ignorant about science. The bridging of this gap in this most influential part of the population is of great urgency. There aro many ways in which tolevision can holp to closo the gap within the framework of the present programme structure.

The main function of a telovision programmo is to appeal to a largo part of the population. While the 'influential crust' shows little interest in science, the remainder of the population is more interested in scientific subjects than any other type of serious programmo. Scientific programmes appear to be of spocial interest to the growing body of technicians in industry: mechanics, plant controllers, radio and electronics exports, eloctricians, welders and a host of others. They seom to be more interesting to mon than to women. Tho degree of interest is shown by the size of the audience, which, for recent scientific programmes, has boen about five million.

In presenting programmes on scientific subjects, the television services aro doing more to influenco Britain's attitude to scienco than any one other medium. Recently, Sir Lawronce Bragg gave a 
series of lecture-demonstrations at the Royal Institution in London which were broadcast over the B.B.C. television network. More people watched each lecture than could have attended in person in the Royal Institution's lecture hall had Sir Lawrence Bragg been prepared to repeat the same lecture every night until the end of the century.

How should science and technology be handled on television? There is room for different approaches. What is suitable for a schools programme, with its captive audience expecting to be taught, is wholly unsuitable for a mid-evening programme. There is a noticeable tendency for the commercial network to play safe and seek programmes which will command tho greatest number at the expense of quality and individual interest. To offset this, the commercial companies occasionally include a 'prestige' programme, sometimes on a scientific subject, which they advertise widely. Nevertheless, the number of scientific programmes from the commercial network is below that from the B.B.C.

The low level of general knowledge about science means that any form of science popularization involves communicating a considerable body of facts before the general argument can be appreciated. The conflicts of ideas are as satisfying as in any of the cultural subjects. The protective screen of facts which must be scaled before the argument can be presented, however, bccomes a powerful deterrent.

Some parts of science, like solid-state physics, or almost the whole of chemistry, have now advanced. so far that the 'fact' barrier is virtually unassailable by non-scientists, and even scientists need to spend a considerable time assimilating the background information. The layman can participate most easily in arguments in those fields of science such as cosmology where relatively little is known; he has fewer facts to master before he reaches the point where he can enter the argument. One of the virtues of cosmology is that the facts aro so difficult to find that almost anyone can put forward his pet theory without much risk of being proved wrong.

Programmes stating only established facts have their place both for schools and entertainment; some of these programmes fall into a dangerous trap. In their efforts to hold as large an audienco as possible they over-dramatize the wonders of science. 'Isn't science wonderful' is an attitude of mind even more dangerous that the prejudice of the 'culture' school. It is responsible for the pseudo-scientific advertisements of the patent medicine manufacturers, for the tooth paste containing additives with magic properties and names which are parodies of chemicals, for the petrols which 'tests prove' all give higher mileage and more power, and for all the detergents which all wash whiter. The aim of science on television is not merely to impart facts and to demonstrate applications, but also to give a feel for the methods and philosophy of science.

There are a fow simple rules for those who wish to popularize science on television. The rules are difficult to obey, particularly within the technical confines of a television performance. First, the programme must be entertaining, otherwise it will not get a sufficiently large audience. When alternative television services become available, this rule can be interpreted less strictly and more highly specialized programmes included. Secondly, the subject must be suitable. In practice this means that it must bo possible to get over the necessary background information within the programme. Thirdly, the method of presentation must be such as to make clear the way in which scientists work. Since the experiment is the primary tool of science, the demonstration experiment has an important part to play here. But, too often, the demonstrations are facile and do not reveal the 'dotective' essence of the scientists' work and the care and skill with which he plans his experiments.

Science programmes have followed two main trends. There have been various series of studiomounted productions in which scientists have described their own work, illustrated it with films and demonstrations simple enough to be transported to the studio. Usually these programmes bring together numbers of specialists who illuminate different aspects of the subject. Their contributions are integrated by a 'link-man', sometimes a scientist himself and sometimes a layman or scientific journalist.

The other approach is to take the television equipment to the laboratory to watch the scientist at work. In principle this method has great attractions. A visit to the actual working environment should give a much greater degree of authenticity than a studio production. But there are disadvantages. It is often difficult to produce a genuine atmosphere within the laboratory because of the problems of introducing cameras. Often the actnal apparatus which a scientist is using is unsuitable for demonstration to a television audience. Moreover, a research worker using the actual experimental apparatus for a demonstration may be more tempted to include qualifications which confuse the main argument than when he is using a simplified version made specially for television. Another problem facing the producers of these outside broadcasts from laboratories is that often it is impossible to tell the whole story within the bounds of a single laboratory. It may be possible to use more than one outside broadcast unit, or to include in the programme film taken at othor laboratories. Where this is not possible, peo ole from other laboratories may have to be 'imported' to deal with some aspects of the subject.

Both studio and outside broadcast science programmes have their faults. Studio programmes tend to be too didactic while the outside broadcast type of programme is too inclined to indulge in showmanship. The strength of telovision is in the impact of personality. Some scientists have become sufficiently familiar with the tochnique to be able to hold their own. They are then in a particularly favourable position to communicate the working ideas of science. The main danger is that the power of personality is so strong that experienced performers are sometimes tempted to uso it as a means of gliding over difficult points.

Why is it that more men like Bragg and Bronowski are not seen on the screen ? The answer lies partly with the scientists and partly with the broadcasting organizations. There is no professional reason why a research worker should wish to try to communicate what he is doing to the lay public. To do so does not help his career; in fact, it may jeopardize it. For the scientist, the final reward is to see his work published in the pages of a learned journal. Often the report is written in a manner which is intelligible only to specialists, since only a few specialists need to read it. A television performer, on the other hand, is afraid that if he makes things appear too simple his colleagues will believe that he cannot be engaged on serious or difficult researches. They may even 
think that he is unaware of the qualifications and detailed side arguments that he has discarded in the quest for simplicity. The broadcasting organizations are themselves responsible partly for the lack of enthusiasm among scientists to take trouble and time over the preparation of programmes. One of the main reasons is that the fees paid to eminent scientists to appear in programmes are often small, much lower than those of light entertainment artists. There is little honour in taking part in a programme that values one's services and skills at 10 guineas.
The relationship between scientists and the broadcasting organizations is important. It is essential that scientists should realize that improvements are needed on both sides. The scientific bodies which preach loudest about the need for scientific popularization could make their biggest contribution by trying to convince their members that an appearance on television is no shameful thing and that a man who gets asked more than once is not necessarily a charlatan.

${ }^{1}$ Presented in J. Roy. Soc. Arts, 104, No. 5064 (November 1961).

\title{
NEW SCIENTIFIC INSTALLATIONS IN FRANCE
}

\begin{abstract}
$\mathrm{A}$
MONG new technological installations described in the July-Sept. 1961 issue of French Science News is one developed by J. Gasnier at the Centre d'Études Nucléaires de Grenoble, Section d'Électronique. This is a device for high-precision temperature regulation below ambient temperature. In order to study the magnetic drag between ambient temperature and $-50^{\circ} \mathrm{C}$., the temperature of an enclosed space is regulated to within $2 / 1,000^{\circ} \mathrm{C}$. This regulation is obtained by adding an additional drift-correction loop to the standard regulation loop. The equipment, which is entirely automatic and independent of the mains, is designed to operate for a 48-hr. regulation period.

L. Malnar, Compagnie Générale de Télégraphie sans Fil, and J.-P. Mosnier, École Normale Supérieure, Paris, have developed an optical pump magnetometer for studying the spatial field: its operation is based on the magnetic resonance of cresium vapour. Resonance transitions are produced by a high-frequency field created by Helmholtz-positioned coils supplied by a generator. The latter is frequency modulated at $80 \mathrm{~Hz}$. in order to cover the resonance ray on both sides of its mean value. The measurement is carried on the $F=4$ transition group, which is assimilated to a single ray of approximately $80 \mathrm{~Hz}$. in width. Prototype sensitivity is at present $\mathrm{I} \gamma$; it is to be increased to $0 \cdot 1 \gamma$.
\end{abstract}

A rapid neutron critical assembly was brought to divergence on March 8 in a military centre of the Commissariat à l'Énergie Atomique. This unit, which has been named Rachel, is the first of its kind in France. It consists of a metallic plutonium core surrounded by the associated control, measurement and safety instruments. It is to be used for investigating the physics of non-decelerated neutrons; it has not been possible to carry out such work with the reactors in service up to the present time, since their moderating substances slow the neutrons down.

L'Office National d'F́tudes et de Recherches Aéronautiques has put two hypersonic wind-tunnels into service, in which the speed of the fluid content is more than five times that of sound. In the first wind-tunnel, long blasts (10-20 sec.) occur at Mach 7 in a $30-\mathrm{cm}$. diameter jet, and simulate pressures in an altitude range of $25-40 \mathrm{~km}$. The second tunnel gives short blasts at approximately Mach 20 in a $50-\mathrm{cm}$. diameter jet. The flow-generating temperature, of approximately $5,000^{\circ}$, is obtained by an electric arc. Blast time, limited to $20 \mathrm{msec}$., none the less allows the measurement of pressure, heat flux and stress on models. The altitude simulated ranges between 30 and $70 \mathrm{~km}$., according to the vehicle under consideration.

\section{MEASUREMENT OF THE THICKNESS OF VACUUM DEPOSITS USING THE ELECTRON MICROSCOPE}

\author{
By Miss D. CHESCOE and J. S. HALLIDAY \\ Research Laboratory, Associated Electrical Industries, Aldermaston Court, \\ Aldermaston, Berkshire
}

\begin{abstract}
R RADLEY $^{1}$ has shown that the condensation of hydrocarbon molecules on surfaces exposed in demountable vacuum systems provides a means for measuring the thickness of vacuum-deposited films when they are afterwards examined in the electron microscopo. The results now to be described show that the accuracy of the new technique is only limited by the resolution of the electron microscope and by real variations in the thickness of each deposit, these being independent of the specimen material. The minimum and maximum limits of film thicknesses that can be measured have also been investigated.
\end{abstract}

\section{Specimen Preparation}

For all but the very thinnest specimens, the method of preparing the specimens is similar to but rather simpler and easier to manage than that described by Bradley $^{1}$. A carbon film about $500 \AA$. thick was depositod $^{2}$ on freshly cleaved mica, and then a narrow strip, 1-2 mm. wide, of the film was romoved by drystripping with 'Sellotapo'. The specimen was then deposited at a known angle, $\theta$, on to the exposed mica strip and at right angles to the edges of the carbon film. Afterwards the combined carbon and specimen film was floated off the mica on to a distilled- 